\title{
A Global Perspective on Psychologists' and Their Organizations' Response to a World Crisis
}

\author{
Germán Gutiérrez $^{\text {a1 }}$, Oscar Barbarin ${ }^{\text {b }}$ (D), Martina Klicperová-Baker ${ }^{\text {CD, }}$, \\ Prakash Padakannaya ${ }^{d}\left(\mathbb{D}\right.$, Ava Thompson ${ }^{e}{ }^{(D)}$, Simon Crowe ${ }^{f}(\mathbb{D}$, \& Brigitte \\ Khoury ${ }^{\mathrm{g}}{ }^{2}$
}

\begin{abstract}
Universidad Nacional de Colombia, Bogotá, Colombia ${ }^{a}$; University of Maryland, College Park, United States of America ${ }^{\text {b }}$; Czech Academy of Sciences, Prague, Czech Republic ${ }^{\mathrm{c}}$; Christ University, Bengaluru, India d; University of the Bahamas, Nassau, Bahamas "; La Trobe University, Melbourne, Australia ${ }^{\mathrm{f}}$; American University of Beirut, Beirut, Lebanon ${ }^{\mathrm{g}}$.
\end{abstract}

\begin{abstract}
Around the world, individual psychologists have stepped up to deliver essential services to address the social and emotional sequelae of the COVID-19 pandemic. Many psychological organizations have also responded to this public health crisis, though their efforts may be less widely recognized. Psychological organizations engaged in preventive and mitigation efforts targeted, among others, the general public, local communities, and high-risk groups such as health care providers. They disseminated mental health information to the general public, trained laypersons to provide psychological first aid, and used research to design and evaluate public health responses to the pandemic. In some countries, psychological organizations contributed to the design and implementation of public health policies and practices. The nature of these involvements changed throughout the pandemic and evolved from reactive to proactive, from local to international. Several qualities appear key to the value, impact, and success of these efforts. These include organizational agility and adaptability, the ability to overcome their political inertia and manage conflict, recognizing the need to address cultural differences, and allocating limited resources to high-risk and resource-depleted constituencies where it was needed most.
\end{abstract}

Keywords

COVID-19; international psychology; organizational response; governance; public policy

\section{RESUMEN}

En todo el mundo, los psicólogos han intervenido de manera individual para prestar servicios esenciales para abordar las secuelas sociales y emocionales de la pandemia del COVID-19. Muchas organizaciones psicológicas también han respondido a esta crisis de salud pública, aunque sus esfuerzos pueden ser menos reconocidos. Las organizaciones psicológicas que participaron en los esfuerzos de prevención y mitigación se dirigieron, entre otros, al público en general, a las comunidades locales y a los grupos de alto riesgo, como los proveedores de atención médica. Difundieron información sobre salud mental al público en general, formaron a personas no profesionales para que prestaran primeros auxilios psicológicos y utilizaron la investigación para diseñar y evaluar las respuestas de salud pública a la pandemia. En algunos países, las organizaciones psicológicas contribuyeron al diseño y la aplicación de políticas y prácticas de salud pública. La naturaleza de estas participaciones cambió a lo largo de la pandemia y evolucionó de reactiva a proactiva, de local a internacional. Varias cualidades parecen ser clave para el valor, el impacto y el éxito de estos esfuerzos. Entre ellas se encuentran la agilidad y la adaptabilidad organizativa, la capacidad de superar su inercia política y gestionar los conflictos, el reconocimiento de la necesidad de abordar las diferencias culturales y la asignación de recursos limitados a los grupos de alto riesgo y con escasos recursos donde más se necesitaban.

Palabras claves

COVID-19; psicología internacional; respuesta organizativa; gobernanza; política pública

\footnotetext{
1 Correspondence about this article should be addressed to Germán Gutiérrez : gagutierrezd@unal.edu.co

2 Conflicts of Interest: The authors declare that the research was conducted in the absence of any commercial or financial relationships that could be construed as a potential conflict of interest.
} 
Una perspectiva global sobre la respuesta de los psicólogos y sus organizaciones a una crisis mundial

In December of 2019, nearly 30 cases of pneumonia of unknown origin were identified in Wuhan, China. The causative agent was later identified by the Chinese Center for Disease Control and Prevention, and named Severe Acute Respiratory Syndrome Coronavirus 2 (SARS-CoV-2). The World Health Organization named the disease COVID-19. By September 20, 2021, nearly 227 million cases and 4.7 million deaths have been confirmed. COVID-19 has affected the whole world, but some regions have been more adversely affected. The aerosol or contact transmission of COVID-19 led to a series of public health recommendations, including physical distancing, hygiene measures, and the use of face masks. The pandemic and public health measures have been controversial, viewed skeptically, and resisted. They have resulted in multi-layered psychological strain related to fear, economic hardship, uncertainty about the future, and grief over the loss of loved ones.

Even before COVID-19, Cooper and Ratele (2014) argued for psychology's involvement in addressing the psycho-social sequelae of pandemics and natural disasters. Barbarin et al. (2021) went further in recommending specific ways psychological organizations could help mitigate the long-term adverse consequences of COVID-19. Although providing direct clinical services around bereavement and reframing stressors as challenges might be beneficial to some, only a limited group could be reached and served in this way. A more significant impact might result from psychology's involvement in training and technical assistance that developed the skills of lay helpers, encouraged mutual support networks, and strengthened a sense of community. Other recommended avenues of assistance included collaboration with NGOs, community leaders, and government. Psychology can use its research expertise to design and evaluate interventions that might address such issues as caution fatigue, disinformation, while increasing acceptance of proven public health strategies.

In addition to Barbarin et al.'s (2021) recommendations for psychology involvement in responding to COVID-19, this paper describes the responses of a group of psychological organizations worldwide and how their responses evolved over the course of the pandemic. The paper provides a context for thinking about psychology's response by discussing the advantages that organizational responses have over individual responses and highlighting organizational qualities that have been associated with the ability of organizations to engage effectively. After presenting examples of who were 
targeted for intervention and the types of interventions used, the paper addresses issues that associations should weigh in advance of developing their response to pandemics and natural disasters in the future. The latter issues include, inter alia, their expertise and resources; selection of intervention targets; lessons learned from prior use of the proposed interventions; potential impediments to implementation; leveraging resources through collaboration with other disciplines and professions; and the value of joint multinational responses.

Psychological organizations offering their expertise to address pandemics and disaster begin with a disadvantage relative to public health and psychiatric organizations. In many countries, the voices of psychologists and other behavioral scientists were not included in the Crisis Management Teams charged with formulating an early response to the pandemic. However, this may be changing as the pandemic's challenges are understood to extend beyond medicine and public health into behavioral, economic, political, and social domains (Janssen \& van der Voort, 2020). Moreover, the value of psychological expertise is becoming apparent with the recognition that effective vaccines and treatment protocols are insufficient to prevent the rapid spread of disease variants and the overwhelming of health care systems. These will have to be supplemented by behavioral strategies such as mask-wearing, social distancing, and handwashing. In addition, the mental health consequences of COVID-19 are severe and can outlast concerns about physical health. For example, the pandemic engenders anxiety, resulting in negative emotions, stigma, and sometimes aggression (Bavel et al., 2020). Individuals with COVID-19 and even those only suspected of infection often experience fear of the consequences; they may be isolated and consequently experience loneliness, sleep disturbances, and depression, amongst other symptoms. They may be consumed with guilt and concern for their loved ones, lose income, encounter discrimination within their social context, and experience diminished wellbeing (Li et al., 2020). Persons not directly affected by the disease may also experience social and psychological consequences, including loss of income, isolation, loss of motivation, boredom, anxiety, depression, aggression, and a variety of other mental health issues ( $\mathrm{Ng}, 2020)$. They may also experience increased spousal or parental abuse and other forms of abusive social interactions (Scholten et al., 2020), that will require psycho-social interventions. Psychological science can be a critical resource to society by identifying and addressing the psycho-social sequelae of COVID-19, proposing ways to maximize compliance with 
public health guidance, and organize service delivery systems to prevent long-term adverse consequences of the pandemic (Barbarin et al., 2021).

\section{Advantages of Organizational Responses}

Psychology is highly relevant, both as a science and a profession, to the challenges of COVID-19. It is an ethical and moral imperative for psychologists to respond with compassion to others' suffering (Seedat, 2014). Psychologists have the opportunity and the obligation to deploy their expertise to contribute to disease management and facilitate the adoption of behaviors to mitigate its spread. In recent decades, psychologists have taken up the challenge both as individual citizens and as professionals through their organizations and multi-disciplinary collaborations with governmental and nongovernmental health systems. Many vital programs and successful efforts to promote coping with pandemics have resulted from these efforts. However, organizational engagement to crises, whether they be natural disasters (e.g., earthquakes), other pandemics (e.g., AIDS), or man-caused events (e.g., forced migration), are more likely to be impactful in the short term and sustainable in the long time.

Although individual initiatives are valuable, the collective action possible through professional organizations and scientific societies has many advantages. First, organizations provide ready-made networks and have a wealth of pre-existing intellectual resources and influence. As institutions, they can make a sustainable commitment; they can tap the resources of affiliated organizational networks, develop alliances with other societies, and project their influence across a broad geographical region. Societies and organizations also generally possess material resources and capabilities individuals do not. They can support initiatives with seed funding from their resources or use their status as fiduciaries to garner funding from governments, foundations, and philanthropic sources. Consequently, organizations can take on more significant projects, adopt a broader view, pursue more ambitious goals, and have a more lasting impact than might be reasonably achieved by individuals acting alone and at a local level.

The collective action of organizations provides the influence, gravitas, and legitimacy that individuals lack. Professional societies and organizations would also have national and global leaders ' attention in an ideal world where public interest would be the main force driving governmental responses. Organizations can coordinate their members and bring in partners from other segments of civil society, such as humanitarian organizations mobilizing their resources. In addition to its capacity for brokering and 
legitimizing scientific claims and disseminating information, collective action can confer an imprimatur on programs and policy recommendations that carry more weight than individuals.

Engaging governmental infrastructure can also be an effective means of involvement by organizations. Although individuals ultimately must implement any program, having the support of science-based professional organizations can make a big difference in its successful adoption. Professional organizations and interest groups constitute an essential network, a vital part of civil society. Their significance stands out, particularly in times of need when traditional societal networks are insufficient, disturbed, dysfunctional, or overwhelmed.

\section{Organizational qualities that facilitate engagement}

National organizations of psychology vary in their stature and in their capacity to act. The International Union of Psychological Science (IUPsyS), the leading global organization of psychological associations, founded in 1951 (Rosenzweig et al., 2000), classifies national psychological organizations based upon their membership, structure, longevity, mission, and national stature. Psychology organizations differ in their mission and resources; these affect their capacity and the scope of their responses. Psychological organizations with a professional focus respond more readily to crises and are more suited to disseminate strategies for coping with the psychological sequelae of pandemics. Scientific organizations are well suited to interpreting basic research implications for maximizing compliance with public health recommendations. Organizations with longer histories, more ample resources, and name recognition are generally better able to intervene in national crises. They can use various approaches and target more levels of society (e.g., individual, local, national, international). Also, organizations with longer traditions are socially recognized, influential, and likely to be called upon when facing crises culminating in a more significant impact.

Local, national, and regional organizations operate within different geographical terrains and have diverse scopes of action. By their very nature, national organizations respond to a constituency that demands agile, specific actions at a local (national) level. National professional and scientific organizations that are well resourced and structured are pre-disposed to make more timely and comprehensive responses to crises. Accordingly, they have the institutional capacity to recruit professionals (either as 
volunteers or contractors). They may even have some financial resources to provide immediate relief even if they cannot address the long-term needs alone.

Regional organizations typically have a broader span than national organizations. They can bring together national associations from a defined geographical area (e.g., Africa, ASEAN region, Europe, Latin America). They do not often create programs but facilitate connections between national organizations to extend programs to a population not likely to receive them without that coordination. Regional organizations offer a significant advantage due to their ability to network with multiple countries with shared interests and needs. For example, the Interamerican Society of Psychology (SIP) created a committee to promote actions across the different countries in the Americas related to mental health, noting a need for guidelines on dealing with the crisis. Following a systematic review, they adopted a series of recommendations directed at psychology practitioners regarding the mental health and psychological wellbeing of the population. How to face new situations associated with crises? How to deal with the expression of psychological symptoms? How to deal with quarantine and physical distancing? How to intervene with particular age groups, including boys and girls, teenagers, and the elderly? How to understand the challenges faced by people with disabilities and help them address those challenges? How to help people affected by mental health problems? How to deal with people living on the street? How to face the humanitarian crisis of refugees, migrants, and displaced people? How to orient yourself concerning sexuality and inherent diversity? How to face grief situations? How to accompany health personnel and other essential activities? How to face abuse, intra-family violence, and gender violence? How to meet problematic consumption? How to address social inequality and discrimination? How to adapt professional psychological care practices to new challenges? (Gallegos et al., 2020). This guide was handy but is not of itself enough. It is essential to coordinate actions that extend or integrate successful programs from one country to another or even the whole region. The following step seems to be engaging leaders and organizations willing to follow or promote these and other actions and recommendations. In October of 2020, leaders from the Latin American region planned a summit to discuss pressing issues associated with the contribution of psychology to the handling of crises in the region and develop a strategy for coordinated action, including national organizations and regional organizations like SIP (Gutiérrez \& Ramírez, 2020).

The Caribbean Alliance of National Psychological Associations (CANPA) established a Disaster Mental Health Committee, coordinating efforts with regional 
stakeholders (e.g., Pan American Health Organization, Red Cross, Caribbean Disaster Management Agency, Caribbean Public Health Agency). Also, each National Member in the region has developed initiatives (e.g., direct service provision and capacity building events) for their specific jurisdiction, often with psychologists from different countries.

International and regional organizations can effectively serve the global community by sharing expertise, strengthening the capacity of less mature or resourced member countries, and developing policies that can be adapted to various scenarios, countries, or regions. For example, the IUPsyS developed a policy for action in times of crisis. The IUPsyS COVID-19 Draft Action Plan draws from previous experience with crises. Still, it recognizes that this health crisis' scale renders some actions insufficient to the specific situation scale. Thus, the leadership of IUPsyS opted to collaborate with regional organizations in its capacity-building initiatives, supporting the development of regional organizations such as the Pan African Union of Psychology Associations and the Central American Union of Psychology Colleges and Associations. It has also collected and organized a list of resources on COVID-19 developed by the various national and regional organizations and offered support and consultation with organizations and countries in need, rather than with organizations and countries with a large capacity for action (Saths Cooper, IUPsyS Past-president, personal communication, October 19, 2020). IUPsyS' capacity-building program has successfully promoted the training of psychologists around the globe in disciplinary and professional up-to-date research methods and professional techniques on emerging areas in psychology. The Advanced Research Training Seminars were held since the early '90s and included topics such as "Coping with adverse conditions" (1992), "Psychology of global environmental change" (1992), "Eco-thinking from a cross-cultural perspective" (1994), "Developing effective health behavior interventions" (1998), and "Stress, Health and Well-being in the Face of Major Trauma" (2006) (Ritchie, 2006; Rosenzweig et al., 2000). More recently, however, capacity building has emphasized strengthening regional and national organizations in their capacity to address important professional, scientific, and societal issues emerging in current times (Pam Maras, IUPsyS President, personal communication November 19, 2020).

\section{Qualities of Engaged Organizations}

Two qualities are critical for effective organizational responses to challenges such as the COVID-19 pandemic. The first is agility, the ability to respond quickly to an 
emerging crisis or challenge (Overby et al., 2006). The second is adaptiveness, the capacity to respond to changing conditions in which conflicting interests are at stake and uncertainty is high (Chaffin et al., 2014). Some psychological organizations exhibited agility in recruiting their members into national task forces. For example, early in the pandemic, the Colegio Colombiano de Psicólogos (Colpsic) created a crisis management group to respond to emergent needs. Initially, the group provided information on the psychological aspects of the pandemic to the general community. Then its members teamed up with mental health hotlines to offer support and information to the general public. The College also created a structure to help citizens access direct psychological assistance by setting up a therapist referral system connecting individuals with psychologists who provided their services pro bono (Rhodes, 2020). This emergency structure remained active until national health care providers reinstated a general mental health system that began to service the country again.

Moreover, the group also targeted hospital medical personnel at risk for mood disorders and provided a training and social support program. Each of these actions was accomplished within months of the initial outbreak in the country. Similarly, psychology organizations in India, Russia, China (de Almondes et al., 2021), and many other countries provided counseling services to phone callers in distress or needing guidance.

Some national organizations recruited volunteer psychologists and laypersons to address the acute deterioration of mental health conditions during quarantine periods. For example, in Ecuador, volunteers were recruited during an early surge of infections and deaths that heightened anxiety in the population. Two groups offered their services at the time of crisis: experts and volunteers from the general public. The experts hit the ground running, while the volunteers required much training and support. Based on that experience, associations are recommended to recruit volunteers selectively, clearly define their tasks, and supervise them regularly (María L. Ramírez, Office of International Affairs-Colpsic, personal communication, April 20,2020). The recruitment of volunteer work must also take into consideration the regulatory framework for the professional practice. For example, in Russia, a lack of proper regulation for psychological services interfered with providing services by volunteer psychologists (de Almondes et al., 2021).

Other national organizations proved their adaptiveness by creating groups of experts, specialized task forces to attend to the urgent needs related to the pandemic. The British Psychological Society organized eight sub-groups addressing different issues related to COVID-19: Adaptations, Behavioural Science, Bereavement and Care of 
Relatives, Community Action, Confinement, Rehabilitation, Research Priorities, Staff Wellbeing, and Working Differently. The continuing work of these groups has resulted in developing a series of documents, videos, and projects that have responded to the dynamic nature of psychological needs in the general and specific populations (see https://www.bps.org.uk/coronavirus-resources).

The Conselho Federal de Psicologia (CFP) and the Sociedade Brasileira de Psicologia (SBP) each assumed their respective roles to guide the practice of psychology during the pandemic in Brazil. The CFP made a registry of psychologists for online services and developed a series of guidelines for psychological services during the COVID-19 pandemic. The SBP established a working group to draw recommendations based on scientific principles and evidence that led to a series of brief but solid publications on different psychological aspects of the crisis. The BSP was also responsible for establishing the TelePSI project in collaboration with the Ministry of Health and other health and educational organizations to offer psychological support to health workers, teachers and students of all levels, and essential workers (de Almondes et al., 2021).

The American Psychological Association (APA) took a different approach and repurposed its international climate action group, which previously worked on psychological contributions to climate change, to respond to COVID-19. Moreover, APA expanded the impact of this effort by collaborating with representatives from many other countries around the globe. This extended international group served as a forum for sharing experiences and initiatives of psychological approaches to pandemic issues. It has also produced and disseminated informational declarations on the prevention of violence at home, psychology's role to serve humanity, and many others. The effectiveness of this group was facilitated by the active participation of representatives from international organizations such as the International Union of Psychological Science (IUPsyS) and the International Association of Applied Psychology (IAAP), and regional organizations such as the European Federation of Psychology Associations (EFPA) and the Interamerican Society of Psychology (SIP). Many national leaders have also encouraged, supported, and ultimately contributed to the larger global initiative's success, now called the Global Psychology Alliance (Amanda Clinton, Senior Director Office of International AffairsAmerican Psychological Association, personal communication, October 1, 2020).

The Federación de Psicólogos de Venezuela (FPV) required both agility and adaptiveness as it lacked resources and was already dealing with a prolonged political and 
social crisis, and the pandemic. Although financial resources are often critical for an organization's capacity to mobilize, their lack does not have to be an insurmountable impediment to helping others. The FPV provides an example of how with little financial resources, they could marshal the human resources of psychologists and rely on the credibility of the profession to offer different kinds of psychological support to their community (Juan C. Canga, FPV President, personal communication, August 28, 2020).

\section{Response coordination in time and scope}

While some disasters are unexpected (e.g., natural disasters, terrorist attacks), others can be prepared for if not prevented. Prevention and early reaction are ethically and economically most advantageous. Nations with rich experience in emergencies were at a particular advantage. For example, Lebanon has faced repeated crises and emergencies related to civil unrest, political and economic instability, spillovers from the Israeli-Palestinian conflict, and the Syrian civil war. COVID-19 was just one more emergency that called upon community solidarity and action, posing one more trial to their extraordinary resilience.

Similarly, Albania had been hit by an earthquake just months before the COVID19 pandemic affected the country. The Order of Psychologists of Albania used the experience from that natural disaster to organize a group of volunteers to offer services during the early emergency and to contribute to the early response of their health system (Rhodes, 2020). Other countries in Asia or Africa, more used to pandemics and defensive strategies, such as wearing face masks, coped particularly well in situations demanding discipline and following authorities' directions. In contrast, countries not used to behavioral restrictions have not fared well with lockdowns or even simple preventative measures such as wearing facemasks. In some cases, demonstrations organized to protest necessary preventive measures produced societal division and polarization. The rapid spread of the infection was facilitated by disagreeing on necessary measures among impacted regions and countries. There were frequent disputes within federated countries and their constituent units, such as Brazil, Germany, the USA, and the independent states of the European Union. Governments' question was whether and how to coordinate, whether restrictions challenge rights and freedoms, whether it is unfair to prevent inhabitants of the most infected regions from free travel. 


\section{Targets of Assistance}

There are many lessons to be learned from the early and helpful interventions by psychological organizations. Their mental health and psycho-social interventions were broadly consistent with the recommendation of the World Health Organization to direct information dissemination, counseling, and other interventions to six groups: the general population; healthcare workers; team leaders and managers in healthcare facilities; care providers for children; older adults, care providers of people with underlying health conditions; and people in isolation (World Health Organization, 2020).

We analyzed the information published on the national organizations' webpages (See https://www.iupsys.net/allaboutpsych/covid-19.html for a list of those organizations). Most of these organizations initially directed their responses to the general public. They later focused on specific local needs, high-risk groups (including children, teachers, and the elderly), psychology peers, and other health professionals.

\section{The General Public}

The initial information intended for the general public mainly provided scientific knowledge about the virus, modes of infection, and its associated risks. It also offered strategies to prevent the spread of infections, emphasizing physical distancing and hygiene. Other specific advice was posted only later. In some cases, psychologists were part of broader efforts to inform the public. For example, in the Czech Republic, psychologists joined an initiative from the general community advocating face masks to prevent contagion. As the first COVID-19 wave approached the country, the government called for the mandatory use of face coverings. However, face masks were not generally available at that time, not even for medical personnel. This gave rise to a voluntary social movement to offer homemade face masks. Within just a few weeks, $91 \%$ of the population owned a homemade face mask (Gorčíková et al., 2020).

This initiative became central to the containment of the spread of COVID-19. Through the Internet, news of this initiative spread worldwide as an effective strategy for preventing coronavirus infection, forcing a change in the recommendations provided by health organizations, notably the WHO. Especially effective was a video (https://www.youtube.com/watch?v=2_WxtSavZR4) that presented the case for using face masks, which was corroborated by Czech scientists explaining why they were effective in preventing contagion, well before empirical studies were published 
supporting their claims (Trnka, 2020). Psychology organizations joined this movement by analyzing the role of volunteering and grass-roots initiatives, often ignored as sources of social change.

In response to the widespread adoption of lockdowns, initial basic information posts were followed by information for more specific populations such as parents, children, teachers, elderly, and vulnerable populations on coping with social isolation. This information articulated the challenges that individuals and families in lockdown would be facing. It aimed to prevent the behavioral and health effects of social isolation, such as loss of social support, loneliness, lack of exercise, increased food consumption, and the loss of structure in daily routines.

To populations without quality Internet service, information was provided by radio, TV, and cell-phone text messaging. Early on, the mass media mainly consulted with physicians for COVID-19-related information; only later were psychologists and other professionals included in the pool of media consultants addressing the emergent psychological issues. In countries that imposed quarantined periods, communication between communities and their leadership was negatively affected. Traditional means of disseminating information (e.g., flyers, megaphones) of local value for many communities were curtailed, and only later were these restored. The disruption of communication due to lockdown was more acute in places where community interaction substitutes for governmental action and services.

\section{The Vulnerable and Disadvantaged}

As indicated previously, given the early quarantine measures, community organizations serving underprivileged sectors of the community often lost touch with their base. The lockdown limited caregivers' free movement, and the fear of infection increased their reluctance to venture out among high-risk clients. This lack of service delivery was particularly marked for people in economically distressed neighborhoods, the homeless, and migrants, who did not receive sufficient or relevant information. For example, lockdown rules did not correctly apply to the homeless, washing hands frequently was meaningless to people without running water, and distancing was impossible for large families living in restricted spaces (Tagat \& Kapoor, 2020; Weible et al., 2020). This is particularly important, as government support for the most vulnerable populations typically was disrupted early on during the pandemic. Under 
quarantine, these populations could hardly be reached by community networks, volunteers, or the police, leaving them affected in social and economic terms and more likely to bypass preventive measures.

Of particular concern are people whose lives depend on institutions. For example, the elderly in senior homes, the hospitalized, the incarcerated (Scholten et al., 2020), migrants in temporary camps, and those under the rule of extreme governmental measures; this is the case of children forcefully separated from their parents on the southern border of the United States seeking to deter migration from Central America (Garrett, 2020). Similarly, there is a concern for exhausted hospital staff, employees who must attend their workplaces, and first responders of all specialties.

Psychological and social services by community psychologists, social workers, and others came to a halt in many cities. In the early stages of the pandemic, psychological services provided to vulnerable populations by volunteers, educational institutions, and NGO organizations were often of an emergency nature and were not systematic or continuous. Only later were the health systems in some countries capable of providing psychological services as part of their regular "health package". However, in general, the COVID-19 pandemic has highlighted the weakness of health systems worldwide in offering quality psychological services to a growing population in need of assistance.

\section{The Psychological Community}

Although no reliable data were initially available on changes in prevalence and incidence of mental health issues, experts informed the psychological community of many individuals' significant emotional and behavioral changes. They were related to uncertainty and isolation, fear for loved ones, loss of income due to isolation measures, loss of social support, and other life changes associated with the pandemic. Although the first mandate for psychologists was self-protection, some national organizations began to form crisis teams and provide guidelines to attend to the population's new psychological needs. Most psychology organizations report that those efforts were initially not organized through the health system, with few exceptions (e.g., Cuba, Taiwan), but were primarily voluntary actions by individual psychologists.

Professional organizations have organized their response to psychologists with information and training on effectively addressing mental health issues during the COVID-19 crisis. This has been done through the development of documents, virtual 
seminars, and panel discussions. For example, the Psychological Society of Ireland created a podcast series directed at psychologists and adapted their supervision strategy for training (Rhodes, 2020). Additionally, many resources have been dedicated to providing psychological services using online platforms (i.e., telepsychology; see, for example, resources published by the British Psychological Society, https://www.bps.org.uk/coronavirus-resources/professional).

Many clinical and counseling psychologists saw their private practices severely affected by the social isolation measures that prevented their clients from reaching them in traditional ways or by changes in their income. At the same time, however, the clients saw their needs for psychological services increase. Solving this paradox has taken time. As with other areas demanding adaptation, the situation promotes ways to address concerns related to the quality of communication and service, privacy issues, ethical considerations, care standards, and even the logistics of financial transactions. These changes also require a regulatory framework, the development of guidelines for proper care, and a clear understanding of the challenges and limitations associated with online services (de Almondes et al., 2021).

Additionally, new opportunities are arising, but at the same time, some challenges remain unresolved. For example, it has become clear that the psychological community cannot continue to ignore psychological services to populations living in remote areas. Despite uncertainty on the quality of online services, governments, with the support of psychological organizations and health providers, must develop strategies and standards for the provision of mental health and other psychological services to those communities that cannot count on face-to-face psychology services (Speyer et al., 2018).

\section{Health Service Providers}

Acknowledgment of the experience of emergency teams in countries heavily affected early in the pandemic (i.e., China, Italy, Spain) led psychologists in many countries to feel the need to offer support services to frontline responders, including medical personnel, especially those in emergency rooms and intensive care units. Information on how to deal with long hours, heavy losses of lives, and especially the threat to their health was initially provided.

Health care workers have reported distress, anxiety, depression, insomnia, and burnout, among other psychological effects (Chew et al., 2020). They had to face high 
levels of uncertainty and lack of control, work overload, shortages of personal protective equipment, increased risk of infection, and make ethical decisions beyond their usual demands. They also were affected by seeing their colleagues infected by the virus. During the initial phases of the pandemic, they had to perform their professional duties without proper treatment guidelines. At a more personal level, they were concerned about infecting their own families or others in their communities, and in some parts of the world, they had to work without receiving what they considered a just compensation for their risk and effort (Ng, 2020; Shechter et al., 2020). In addition to these issues, psychologists offering support to health care personnel report social rejection and ostracism as a particularly painful source of stress associated with frontline workers' essential role during this crisis in many countries worldwide. Some health workers encountered rejection and isolation from their neighbors and even unknown individuals who identified them by their uniforms in supermarkets or public transportation, assuming a heightened risk of being infected and posing a danger to others.

Psychology organizations began to offer direct support in hospitals and institutions of health care. These efforts have taken several forms, including instructions and guides designed for coping, exercise, yoga, meditation, psychotherapy, counseling and self-guided counseling, and support groups (Shechter et al., 2020). In addition to professional assistance, health care personnel also used alternative coping skills, especially faith-based support and social support from colleagues, friends, and family. However, it was observed that medical doctors often do not use these special services due to their cultural context, mainly the social role and status, which prevented them from showing vulnerability under conditions of demand and stress. Younger, less specialized physicians participated more willingly in workshops addressing mental health issues. In contrast, older, highly specialized physicians were generally unresponsive to their hospitals' services (Magnolia P. Ballesteros, Psychology coordinator for hospital services-Universidad Nacional de Colombia, personal communication, October 25, 2020).

A creative initiative was developed by a collaboration among the Lomonosov Moscow State University, the Russian Academy of Education, the Russian Psychological Society, and the Federal Medical Biological Agency of Russia. It is called "psychological thermometers", an online instrument to measure emotional state in COVID-19 patients and health workers, that provides immediate feedback and offers self-help measures as well as resources to be found in the facilities where they were being treated or worked 
(de Almondes et al., 2021). The impact of this and other initiatives on the mental health of their target populations should be of great interest to the psychological and health providers' communities.

\section{Intervention Strategies}

\section{Types of responses}

As the situation developed and psychologists apprehended their clients' newer needs, they shifted focus in their interventions. This was confirmed by reviewing national organizations' web pages at three different points in time (in April, July, and October 2020), which showed the following sequence of actions.

Most of the early response centered on providing information on COVID-19, its medical and psychological effects. This type of response addressed the uncertainty, especially the need for information to evaluate the threatening situation's risk. Information was helpful for risk assessment and a modulator of emotion that drives the initial human response to threat (Bavel et al., 2020). Later, guides, checklists, manuals directed at professionals, and self-help materials directed at the public, were published. By then, peak organizations had recognized gaps in their contributions to their constituents and the community and had been able to collect resources to address those gaps.

Research and policy making only became part of the psychologists' response later in the pandemic but have become an essential part of the growing repertoire of psychological responses. Once local and immediate responses had addressed pressing issues, organizations changed from being providers of actions and direct service delivery to serve at a different level. They began to act as planners to collect and redress resources, especially governments at local and regional levels. In other words, organizations began moving from the operational to the strategic levels of action (Weible et al., 2020). This role change demanded social recognition of the behavioral sciences, admitting that they can provide reliable information and technology to address the issues at hand, namely those of mental health and prevention in the context of the health crisis.

The responses mentioned above can also be viewed as two-dimensional. First, there was a clear shift from reactivity to the emergency to more proactive, selective, and extensive views. The second dimension can be seen as a gradual shift from molecular responses (addressing specific problems) toward more molar levels of action and analysis (solving the more significant problems resulting from the pandemic's general effects). 


\section{Disseminating information to promote coping}

Based on knowledge often derived from well-established psychological areas such as clinical, community, organizational, and health psychology, guides, checklists, and manuals were provided, especially on relevant websites of national psychological organizations and Ministries of Health, where lectures, workshops, and other training services were offered. First, as noted earlier, information on the health effects of the virus (including prevalence, incidence, lethality, vulnerable populations, and others), and the psychological impact of the measures taken by governments to slow contagion in the population (effects of isolation on social life, family life, productivity, loss of income, as well as specific psychological effects including aggression, anxiety, depression, etc.). This initial response was followed by more technical information on dealing with those situations to prevent the aforementioned effects or respond to these after they have manifested.

Information is vital at times of uncertainty to assess risks. However, high-quality and measured information are not always readily available. On the contrary, social media may offer imprecise information or outright lies and hoaxes; additionally, media networks were constantly crowded with information on COVID-19 as if nothing else was happening in the world. Some analysts have referred to this complex phenomenon as "Infodemic", an excessive amount of information concerning a problem, often accompanied by the rapid spread of misinformation, propagated through informal and formal networks, making the solution to the problem more difficult. Some authors have expressed concern about exposure to too much information, contributing to anxiety, uncritical acceptance of potentially false or exaggerated information, and attributions on the responsibility that may be more in line with political discourse than objective analysis (Scholten et al., 2020).

During the early stages of the pandemic, many broadcasting stations would show permanent "breaking news" alerts, concentrating on COVID-19 related information. Infodemic was also widespread in social media venues such as Facebook, Twitter, Instagram, YouTube, etc. Studies on the information in these platforms show that information overload has essential effects on self-esteem, stress, and anxiety, especially under uncontrollable situations. However, some organizations and groups have effectively used those same platforms to disseminate relevant and reliable information. For example, in Singapore, the government used a WhatsApp channel to provide official 
information on COVID-19 measures that provided reliable information, countering other information from less trustworthy sources (Liu \& Tong, 2020). Psychology's role in the management of misinformation on COVID-19 has been suggested. Still, actual trials of social interventions using fact-checking, inoculation, and nudging for discussion and accuracy testing remain to be systematically used and analyzed (Bavel et al., 2020). The Russian Psychological Society made a sustained effort to offer interviews in regional and federal media outlets on mental health issues and coping strategies for different populations during the pandemic and offer fact-checking on fake news related to psychological issues (de Almondes et al., 2021).

\section{Collaborating with Governments and influencing public policy}

Interactions of psychological organizations with governments are often fraught with difficulty, especially with populist ones that have tended to dismiss science in general and the behavioral sciences in particular. Political tensions and disagreement add complexity and must be considered in psychological outreach design that involves collaboration or consultation with governments. However, there are many examples of successful cooperation with governments.

Some governments established "Crisis Committees" and included psychologists and a team of physicians, politicians, and economists. Psychologists experienced in dealing with crises can often be found in national psychological organizations with Disasters, Crisis, and Trauma sections (e.g., see European Federation of Psychologists' Associations source website http://disaster.efpa.eu/resources/ressources-concerningCOVID-19/). Further cooperation with governments came mostly from psychologists already working in state agencies in the health, welfare, and education. Organizations began to interact with governments at local levels and then at national levels, providing advice on the psychological impact of COVID-19 and containment measures. Some psychological organizations have advised the various branches of government on mental health policy and addressed concerns on information management and support for citizens in remote areas and abroad who were stranded during the early times of national borders closing and air travel suspension.

Highly centralized government bureaucracies tend to discount or suppress problems that may give the central government's appearance of failure. This has been the interpretation of the Chinese local governments' delayed response during the early stages 
of the pandemic (Zhou, 2020) and of the prolonged refusal to admit WHO investigators to the assumed ground zero. Tensions between technical and bureaucratic accounts of a crisis are often resolved early by suppressing information or failing to acknowledge the novel situation. After higher hierarchical levels acknowledge the critical situation, however, bureaucracies might turn from ineffective to practical by using the same channels of communication and coordination that support day-to-day stable actions. Thus, bureaucracies do not necessarily impede adaptation, but they may delay it, depending on the political factors at play. This is not restricted to autocratic governments but may also be observed in populist or democratic governments at high-stakes political stages.

Psychological organizations do not have large bureaucracies, but psychologists are sometimes part of systems in which they may serve that role. For example, since January 27, 2020, the National Health Commission of China published a set of "Principles for Emergency Psychological Crises Intervention for COVID-19 pneumonia epidemic", accompanied by a series of recommendations and instructions indicating that those principles should be applied under the guidance of mental health professionals. Those guidelines included specific actions such as understanding mental health issues in different populations affected by COVID-19, identifying people at risk of suicide and aggression, and providing appropriate psychological interventions. They also defined populations in need of action at a variety of priority levels. Level 1 referred to the most vulnerable to mental health issues, including hospitalized patients, frontline health professionals, and administrative staff. Level 2 included isolated patients. Level 3 included family members, colleagues, and friends of individuals in levels 1 and 2. Finally, level 4 included the general public affected by prevention measures (Li et al., 2020). The literature has not analyzed how those guidelines may have been applied or how they may have impacted the general population.

Other governments acknowledged the need for measures to support mental health in the population during the pandemic. However, in many cases, those measures were limited to the publication of resource materials. It was also unclear whether psychology organizations played a role in those proposed measures (e.g., India; de Almondes et al., 2021).

An important exception to delayed participation in government actions has been Taiwan's response to the pandemic. It shows that involving psychologists and integrating psychological advice within the preventive measures will significantly contribute to the effective management of the health crisis. In Taiwan, the government included many 
psychological strategies amongst the early measures to address the pandemic. These included frequent briefings by the Ministry of Health and Welfare directed at the general public, reducing uncertainty, anxiety, and panic, information on coping strategies, and creating a hotline to attend to any concerns related to COVID-19 and its effects. Local governments later created other psychological counseling hotlines. Other measures were directed at vulnerable populations, health care workers, hospitalized individuals, and bereaved families (Hwang et al., 2020).

The latest response identified is the development of proposals or support for public policy. Prestigious or politically connected social research organizations and universities receive requests for conceptual, methodological, and empirical support for public policy in cases in which governments are inclined to see science in a positive light. Unfortunately, governments often see psychology as a servant eager to help whenever there is an interest for its expertise. However, they do not see psychologists as partners who can be brought into policy planning and analysis. This is a crucial point on which psychologists need to focus. Collaborations with other disciplines such as sociology, economics, or public health may help to integrate psychological consideration into public policymaking going forward.

Behavioral science has a lot to offer to policymakers, decision-makers, and leaders. First, by explaining how humans behave in crises. For example, contrary to common belief, most people do not panic under crises and do not act selfishly. They are willing to follow consistent, understandable rules enforced by community leaders or authorities if they can develop a sense of social identity with fellow survivors (Drury, 2018). Second, some basic social concepts such as trust, identity, social norms, leadership, and authority, may be used to promote rule-following, behavior modeling, and prevent polarization and biased reasoning. Third, understanding how social networks function might provide insight into how infections spread and how to decrease the risk of spreading by seeking cooperation from specific social agents that are more likely to be at the center of social networks (Bavel et al., 2020).

Many public policies demand trusting others with one's private information, trusting authorities to make decisions that benefit most of the population, and making good use of public resources. Corrupt leaders are often incapable of engaging their communities, damage authorities' capacity on all levels, and discourage people from complying with the rules. In the current crisis, some populist leaders have enticed people against the preventive rules. They have ostentatiously modeled their behavior by not 
wearing the masks themselves, ridiculed compliant behavior, opposed preventive measures by health and civil authorities, and even used their authority to undermine sound preventive measures.

\section{Approaching cultural differences}

Different cultures have different attributions as to the causes of health and illness. Cultural factors may influence how symptoms might be recognized, when and how to seek medical care, and proper treatments. Culture may also prescribe how ill persons should relate to other members of the community and the sense of responsibility of the individual toward other members of the community when self or others get ill. Thus, public health actions should consider cultural characteristics to prevent the spread of infection effectively, respond to the need for medical care among individuals or clusters in the population, and respond to the application of vaccines as they become increasingly available to the public. For example, identifying cultural factors might be important when trying to understand why populations in some countries have complied more precisely with instructions from the authorities or are more willing to accept the vaccine. In contrast, others have actively resisted simple basic instructions such as wearing a face mask, exercising physical distancing, or receiving vaccination (Biddlestone et al., 2020; Sallam, 2021).

The concepts of individualism and collectivism have been effectively used to compare different cultures across situations. Collectivist societies have been observed to adhere better to social norms as a means of maintaining social harmony. In individualistic societies, personal freedom is promoted over social harmony, and norm compliance is reduced or relativized. This dual individualism vs. collectivism dimension has been further complemented by the idea of how much an individual accepts inequality in its society (vertical individualism and collectivism) or prefers equality (horizontal individualism and collectivism). Thus, vertical individualism is significantly associated with non-compliance with physical distancing, whereas both vertical and horizontal collectivism predict physical distancing compliance (Biddleston et al., 2020). Overall, it is accepted that collectivistic societies are more likely to respond as a community, making them more effective in recovering from crises.

The early information on the pandemic, its consequences, and preventive measures tended to ignore cultural differences. With a few exceptions (e.g., Saban et al., 
2020), actions have been directed at the majority of the population, with little involvement of minority communities being evident in the development of the programs and public health actions. However, understanding, respecting, and adopting cultural differences is essential for practical work within all heterogeneous societies. This is especially necessary for highly diverse countries (e.g., India), where a unique set of recommendations might not be effective in prevention, treatment, and rehabilitation (Tagat \& Kapoor, 2020). Using cultural references in connection with preventive measures and understanding relevant social sanctions and rewards might, in combination, become more effective than appealing to discourses that contradict deeply held beliefs in specific populations.

Integrating cultural sensitivity in public health measures has sometimes been accomplished by working with community or religious leaders. For example, many Christian pastors changed how they share communion to prevent sharing a chalice or a cup and decrease close contact among individuals. Many Jewish and Muslim holidays have been postponed by their religious authorities (Bruns et al., 2020). In those cases in which community and religious leaders have worked closely with authorities and the messaging has been tailored to those communities, the results of public health actions have been more effective (see Saban et al., 2020, for an example of the Arab population in Israel). Sometimes, however, these measures run contrary to the instrumental interests of religious and other leaders who may benefit from keeping their communities closely engaged and refuse enlightenment either for economic, ideological, or political gain.

Although a certain level of success has been attained with some communities, other conservative religious groups have been reluctant or openly opposed to preventive measures during the COVID-19 pandemic, leading to higher levels of contagion among their community members. For example, in the case of the ultra-Orthodox Jewish population in many places around the globe. This religious community is highly dependent on regular family and community interactions, follows an educational system that often contradicts science, uses limited technology to communicate with others, and distrusts non-religious authorities. These characteristics have been identified as sources of enhanced risk for contagion (Pirutinsky et al., 2020; Taragin-Zeller et al., 2020).

The New Zealand Psychological Society (NZPsS) is an example of a psychological organization that has responded more readily to their indigenous communities, acknowledging their needs during the pandemic. The NZPsS has published several resources directed at the Maori population and the Pacific Peoples (see 
https://www.psychology.org.nz). The documents are not mere translations from English, but they are tailored especially for the indigenous communities in New Zealand. A similar multicultural approach has been followed by the Caribbean Alliance of National Psychological Associations (CANPA), which has published documents related to COVID-19 in English, Spanish and French/Kreyol, the main languages of the insular region of the Caribbean. CANPA has screened all documents for relevance to regional $\begin{array}{llll}\text { characteristics and psychological } & \text { andice }\end{array}$ http://canpanet1.cloudaccess.host/index.php/cvresponse).

Empirical studies consistently show that the pandemic has increased inequality and has disproportionally affected those facing social, educational, and economic hardship that had existed before the pandemic, especially so for indigenous peoples (Pillay \& Barnes, 2020; Power et al., 2020). There is a clear trend in the social sciences towards building on humanistic traditions and adopting a culturally sensitive approach. Psychology undoubtedly belongs to those disciplines, trailblazers of culturally sensitive policies and ethical, socially responsible principles.

\section{Conclusion}

We expect these illustrations and their lessons to inspire others to emulate them in future pandemics and natural disasters. This paper argues for professional associations and societies' important role and responsibility by illustrating how psychology organizations have acted. It has recounted a pattern of progressive involvement and cited examples of what societies can do. While the example is psychology, it offers a template for targeted action, a developmental process, and resource utilization applicable to various disciplinary associations that integrate science and public service.

Psychology has accumulated a large body of knowledge on risk perception, compliance, health behavior, emotion, cognition, learning, social behavior, and many other domains. They provide information on how humans face sudden changes in their environment and behave under conditions promoted by preventive measures during pandemics and other natural and human-made crises. All this knowledge can be used effectively in public policy and decision-making, but the transition from basic science to applied action is challenging and demands time and resources. Scientific and professional organizations can be important drivers of this connection and translation of psychological knowledge to help societies in regular times and crises. 
The inductive approach of the present article draws upon the experience of many organizations worldwide who have faced the COVID-19 pandemic and responded at local, national, regional, and international levels through cooperation, and often initially, by individual action. During the present historical period, failures and achievements will be the lines to draw a road map to guide future planning and responses. In the process, it will also be the basis for renewal and adaptation, not only of the structure and functioning of those organizations but also for evaluating training and quality standards of professional practice.

The COVID-19 pandemic, as was the case for the spreading of the Spanish flu pandemic of 1918, has been influenced by behavioral factors (see Soper, 1919). Today's psychology is different from that of 1918. One hundred years later, psychology has a robust body of knowledge and practical techniques that provide the building blocks for a scientific approach to understanding human behavior in exceptional situations and improving its condition, subjective experience, and objective conduct. Scientific and professional organizations must strive to turn that knowledge and skill into coordinated action to benefit society in collaboration with other institutions. In the present article, we have presented numerous examples of Psychology's professional associations distinguishing themselves as the appropriate vehicle through which the knowledge of the discipline can be translated for humanity's service.

Nevertheless, Psychology remains low on the health priority response of most countries, something that has to change. The targets and range of interventions represented in the sample of psychology organizations reviewed in this article are broad, and for the most part, consistent with the experiences and recommendations of international bodies such as the UN and its World Health Organization. A significant challenge is raising the level of intervention from local to national and from national to international. This will require a greater level of cross-national cooperation, particularly in sharing resources with under-resourced countries and organizations, whether money, information, human resources, or life-saving vaccines. Psychology can play a significant role in creating a climate of enlightened self-interest that will lead those with resources to share with those without them, starting with other psychological organizations and expanding to other levels. 


\section{References}

Barbarin, O., Khoury, B., Klicperova-Baker, M., Gutiérrez, G., Thompson, A., Padakannaya, P, Crowe, S. (2021). Psychological science and Covid-19: An agenda for social action. American Journal of Orthopsychiatry, 91 (3), 412 422. https://doi.org/10.1037/ort0000549

Bavel, J. J. V., Baicker, K., Boggio, P. S. et al. (2020). Using social and behavioural science to support COVID-19 pandemic response. Nature Human Behaviour, 4, 460-471. https://doi.org/10.1038/s41562-020-0884-Z

Biddlestone, M., Green, R., \& Douglas, K. M. (2020). Cultural orientation, power, belief in conspiracy theories, and intentions to reduce the spread of COVID19. British Journal of Social Psychology, 59(3), 663-673.

Bruns D. P., Kraguljac N. V., Bruns T. R. (2020). COVID-19: Facts, cultural considerations, and risk of stigmatization. Journal of Transcultural Nursing, 31(4), 326-332. https://doi.org/10.1177/1043659620917724

Chaffin, B. C., Gosnell, H., \& Cosens, B. A. (2014). A decade of adaptive governance scholarship: synthesis and future directions. Ecology and Society, 19(3), 56. http://dx.doi.org/10.5751/ES-06824-190356

Chew, N., Lee, G., Tan, B., Jing, M., Goh, Y., Ngiam, N., Yeo, L., Ahmad, A., Ahmed Khan, F., Napolean Shanmugam, G., Sharma, A. K., Komalkumar, R. N., Meenakshi, P. V., Shah, K., Patel, B., Chan, B., Sunny, S., Chandra, B., Ong, J., Paliwal, P. R., ... Sharma, V. K. (2020). A multinational, multicentre study on the psychological outcomes and associated physical symptoms amongst healthcare workers during the COVID-19 outbreak. Brain, Behavior, and Immunity, 88, 559-565. https://doi.org/10.1016/j.bbi.2020.04.049

Cooper, S., \& Ratele, K. (2014). Psychology Serving Humanity. Psychology Press.

de Almondes, K. M., Bizarro, L., Miyazaki, M. C. O. S., Soares, M. R. Z., Peuker, A. C., Teodoro, M., Modesto, J. G., Veraksa, A. N., Singh, P., Han, B., \& Sodi, T. (2021). Comparative Analysis of Psychology Responding to COVID-19 Pandemic in Brics Nations. Frontiers in Psychology, 12. https://doi.org/10.3389/fpsyg.2021.567585

Drury, J. (2018). The role of social identity processes in mass emergency behaviour: An integrative review. European Review of Social Psychology, 29 (1), 38-81. https://doi.org/10.1080/10463283.2018.1471948

Gallegos, M., Zalaquett, C., Luna, S. E., Mazo-Zea, R., Ortiz-Torres, B., PenagosCorzo, J. C., Portillo, N., Torres Fernández, I., Urzúa, A., Morgan Consoli, M., Polanco, F. A., Florez, A. M. \& Lopes Miranda, R. (2020). Cómo afrontar la pandemia del coronavirus (COVID-19) en las Américas: recomendaciones y líneas de acción sobre salud mental [How to face the coronavirus pandemic (COVID-19) in the Americas: recommendations and lines of action on mental health] Revista Interamericana de Psicología/Interamerican Journal of Psychology, 54, (1), e1304. https://doi.org/10.30849/ripijp.v54i1.1304

Garrett, T. M. (2020). COVID-19, wall building, and the effects on Migrant Protection Protocols by the Trump administration: the spectacle of the worsening human rights disaster on the Mexico-U.S. border. Administrative Theory \& Praxis, 42 (2), 240-248, https://doi.org/10.1080/10841806.2020.1750212

Gorčíková, M., Šafr, J., Spurný, M., Klicperová-Baker, M., Děchtěrenko, F., \& Poláčková Šolcová, I. (2020, May 20). Kdo šil roušky a dobrovolně 
pomáhal v čase koronakrize? [Who sewed the face masks and volunteered during the corona crisis?] Press release. Institute of Sociology, Czech Academy of Sciences.

https://www.soc.cas.cz/aktualita/kdo-sil-rousky-dobrovolne-pomahal-v-casekoronakrize

Gutiérrez, G. \& Ramírez, M. L. (2020). Latin American and Caribbean summit of psychology associations. IUPsyS Bulletin, 12(5), 3. https://www.iupsys.net/dotAsset/415e0417-adca-49fa-a4aa-62e1f789841f.pdf

Hwang, T., Lin, Y., Shen, L., Tang, L., \& Lapid, M. (2020). How Taiwan prevented the outbreak of COVID-19: A focus on psychological strategies and measures. International Psychogeriatrics, 32(10),1121-1124. doi: $10.1017 / \mathrm{S} 1041610220001568$

Janssen, M., \& van der Voort, H. (2020). Agile and adaptive governance in crisis response: Lessons from the COVID-19 pandemic. International Journal of Information Management, 55, 102188, 1-7 https://doi.org/10.1016/j.ijinfomgt.2020.102180.

Li, W., Yang, Y., Liu, Z. H., Zhao, Y. J., Zhang, Q., Zhang, L., Cheung, T., \& Xiang, Y. T. (2020). Progression of Mental Health Services during the COVID-19 Outbreak in China. International Journal of Biological Sciences, 16(10), 1732-1738. https://doi.org/10.7150/ijbs.45120

Liu, J. C. J., \& Tong, E. M. W. (2020). The Relation Between Official WhatsAppDistributed COVID-19 News Exposure and Psychological Symptoms: CrossSectional Survey Study. Journal of Medical Internet Research, 22(9). e22142. doi: $10.2196 / 22142$

Ng, L. L. (2020). Psychological states of COVID-19 quarantine. Journal of Primary Health Care, 12(2), 115-117. https://doi.org/10.1071/HC20030

Overby, E., Bharadwaj, A., \& Sambamurthy, V. (2006). Enterprise agility and the enabling role of information technology. European Journal of Information Systems, 15(2), 120-131. https://doi.org/10.1057/palgrave.ejis.3000600

Pillay, A. L., \& Barnes, B. R. (2020). Psychology and COVID-19: impacts, themes, and way forward. South African Journal of Psychology, 50(2), 148-153. https://doi.org/10.1177/0081246320937684

Pirutinsky, S., Cherniak, A. D. \& Rosmarin, D. H. (2020). COVID-19, mental health, and religious coping among American Orthodox Jews. Journal of Religious Health, 59, 2288-2301. https://doi.org/10.1007/s10943-020-01070-z

Power, T., Wilson, D., Best, O., Brockie, T., Bourque Bearskin, L., Millender, E., \& Lowe, J. (2020). COVID-19 and Indigenous Peoples: An imperative for action. Journal of Clinical Nursing, 29(15-16), 2737-2741. https://doi.org/10.1111/jocn.15320

Rhodes, E. (2020, November 24). No normal crisis. The Psychologist. https://thepsychologist.bps.org.uk/nonormalcrisis

Ritchie, P. L. J. (2006). Annual Report of the International Union of Psychological Science (IUPsyS) to the International Council for Science (ICSU), International Journal of Psychology, 41(6), 571-579. https://doi.org/10.1080/00207590601020713

Rosenzweig, M. R., Holtzman, W. H., Sabourin, M, \& Bélanger, D. (2000). History of the International Union of Psychological Science (IUPsyS). Psychology Press.

Saban, M., Myers, V. \& Wilf-Miron, R. (2020). Coping with the COVID-19 pandemic - the role of leadership in the Arab ethnic minority in Israel. 
International Journal of Equity in Health, 19, 154. https://doi.org/10.1186/s12939-020-01257-6

Sallam, M. (2021). COVID-19 vaccine hesitancy worldwide: A concise systematic review of vaccine acceptance rates. Vaccines, 9(2), 160. https://doi.org/10.3390/vaccines9020160

Scholten, H., Quezada-Scholz, V. E., Salas, G., Barria-Asenjo, N. A., Molina, R., García, J. E., Julia Jorquera, M. T., Marinero Heredia, A., Zambrano, A., Gómez Muzzio, E., Cherone Felitto, A., Caycho Rodríguez, T., ReyesGallardo, T., Pinochet Mendoza, N., Binde, P. J., Uribe Muñoz, J. E., Bernal Estupiñán, J. A. \& Somarriva, F. (2020). Abordaje psicológico del COVID19: una revisión narrativa de la experiencia latinoamericana [Psychological approach to COVID-19: a narrative review of the Latin American experience]. Revista Interamericana de Psicología/Interamerican Journal of Psychology, 54(1), e1287-e1287.

Seedat, M. (2014). Mobilizing compassionate critical citizenship and psychologies in the service of humanity. In S. Cooper \& K. Ratele (eds). Psychology Serving Humanity. (pp. 1-17). Psychology Press.

Shechter, A., Diaz, F., Moise, N., Anstey, D. E., Ye, S., Agarwal, S., Birk, J. L., Brodie, D., Cannone, D. E., Chang, B., Claassen, J., Cornelius, T., Derby, L., Dong, M., Givens, R. C., Hochman, B., Homma, S., Kronish, I. M., Lee, S., Manzano, W., ... Abdalla, M. (2020). Psychological distress, coping behaviors, and preferences for support among New York healthcare workers during the COVID-19 pandemic. General hospital psychiatry, 66, 1-8. https://doi.org/10.1016/j.genhosppsych.2020.06.007

Soper, G. A. (1919). The lessons of the pandemic. Science, 49(1274), 501-506. http://www.jstor.org/stable/1642775

Speyer, R., Denman, D., Wilkes-Gillan, S., Chen, Y., Bogaardt, H., Kim, J., Heckathorn, D., \& Cordier, R. (2018). Effects of telehealth by allied health professionals and nurses in rural and remote areas: a systematic review and meta-analysis. Journal of Rehabilitation Medicine, 50, 225-235. doi:10.2340/16501977-2297

Tagat, A., \& Kapoor, H. (2020). Go Corona Go! Cultural beliefs and social norms in India during COVID-19. Journal of Behavioral Economics for Policy, 4, COVID-19 Special Issue, 9-15. https://ideas.repec.org/a/beh/jbepv1/v4y2020isp9-15.html

Taragin-Zeller, L., Rozenblum, Y., \& Baram-Tsabari, A. (2020). Public engagement with science among religious minorities: Lessons from COVID-19. Science Communication, 42(5), 643-678. doi:10.1177/1075547020962107

Trnka, S. (2020, July 20). First in Masks? How Czechs Wore Face Masks When There Weren't Any Available. Somathosphere. Science, Medicine, and Anthropology. http://somatosphere.net/2020/first-in-masks.html/

Weible, C. M., Nohrstedt, D., Cairney, P., Carter, D. P., Crow, D. A, Durnová, A. P., Heikkila, T., Ingold, K., McConnell, A. \& Stone, D. (2020). COVID- 19 and the policy sciences: initial reactions and perspectives. Policy Sciences, 53, 225-241. https://doi.org/10.1007/s11077-020-09381-4

World Health Organization (2020, March 18). Mental health and psycho-social considerations during COVID-19 outbreak. https://apps.who.int/iris/bitstream/handle/10665/331490/WHO-2019-nCoVMentalHealth-2020.1-eng.pdf 
Gutiérrez, Barbarin, KlicPerová-BAKer, PAdAkannaya, Thompson, Crowe, \& Khoury

Zhou, X. (2020). Organizational Response to COVID-19 Crisis: Reflections on the Chinese Bureaucracy and Its Resilience. Management and Organization Review 16:3, July, 473-484. https://doi.org/10.1017/mor.2020.29

Received: 2021-09-20 Accepted: 2021-09-27 